\title{
Erratum to: Epistemic Closure and Epistemic Logic I: Relevant Alternatives and Subjunctivism
}

\author{
Wesley H. Holliday
}

Published online: 20 January 2015

(C) Springer Science+Business Media Dordrecht 2015

\section{Erratum to: J Philos Logic}

\section{DOI 10.1007/s10992-013-9306-2}

Note to reader: due to an error in the production phase, a previous version of this article with the same DOI contains incorrect cross-references. The article with this note is the final article.

The online version of the original article can be found at http://dx.doi.org/10.1007/s10992-013-9306-2.

W. H. Holliday $(\square)$

Department of Philosophy, University of California, 314 Moses Hall \#2390, Berkeley, CA 94720-2390, USA

e-mail: wesholliday@berkeley.edu 